\title{
Alarm Calls of the Australian Magpie (Gymnorhina tibicen): Predators Elicit Complex Vocal Responses and Mobbing Behaviour
}

\author{
Gisela Kaplan*, Gayle Johnson, Adam Koboroff and Lesley J. Rogers
}

Centre for Neuroscience and Animal Behaviour, University of New England, Armidale, NSW 2351, Australia

\begin{abstract}
Mobbing calls are produced by many avian species as part of a defence strategy against predators. However, as most studies have described small prey species, little is known of mobbing by species large enough to inflict harm on the predator when working cooperatively. We investigated the mobbing calls of the Australian magpie (Gymnorhina tibicen tibicen), a large, territorial songbird known to be exceptionally vigilant and to attack predators. We were particularly interested in this species because it has a very large vocal repertoire. Magpie groups $(\mathrm{N}=45)$ in semi-rural and rural localities were presented with taxidermic specimens of three predators, two species of eagle and a monitor lizard, the latter known to be a risk to their eggs and nestlings. We identified five distinct types of alarm calls, one of which (a complex, tonal call of more than two syllables) was elicited almost exclusively by the eagles in environments where they are known to be a threat to magpies. This alarm call usually preceded intense swooping attacks of the eagle models and often continued during the attacks. A harsh and noisy call of one syllable was the most frequently produced call and appeared to indicate level of arousal. The lizard did not elicit the multi-syllable call or any swooping attacks but it did elicit the harsh call. Some other call types showed less stimulus specificity although a two-syllable call was elicited more commonly by the eagles than lizard. Hence, this species has an acoustically complex, multi-syllable alarm call to signal the presence of an aerial predator in contexts of genuine threat, and this call is markedly different from the harsh single-syllable call, which indicates arousal level and is used most frequently when mobbing a monitor lizard.
\end{abstract}

Key Words: Australian magpie, alarm calls, communication, mobbing.

\section{INTRODUCTION}

Alarm calls are a class of vocalisations of special interest to researchers studying the evolution of signal structure and function. They may provide information to others (usually conspecifics) about the presence and kind of predator [1], indicate levels of arousal (imminence of danger) and, more often than hitherto thought, also provide information about the age or sex of the sender [2-4]. In American crows (Corvus brachyrhynchus) individuals can be identified by alarm call structure alone, which may be adaptive if vigilance and approach urgency depend on the reliability or family membership of the alarm signaller [5]. It has also been asked whether alarm calls always signify actual threat from a known predator of the species or simply express nonspecific fear. Tits, for instance, use alarm calls even when harmless species pass by [6]. The assumption is, however, that most alarm calls most of the time identify situations of actual risk.

Apart from being prey species, many of the species found so far to have referential alarm calls [7], meaning that they signal differences in types of predator [8]), are grounddwelling [9]. From an evolutionary point of view, it seems convincing to surmise that it is of great advantage to a group of animals living at high risk of predation to have evolved an

*Address correspondence to this author at the Centre for Neuroscience and Animal Behaviour, School of Science and Technology, Faculty of Arts and Science, University of New England, Armidale, NSW 2351, Australia; Tel: +61-2-6775 3113; Fax: +61-2-6773 3452; E-mail: gkaplan@une.edu.au auditory warning system capable of signalling accurately about the proximity and type predators (discriminating between aerial and ground predators, for example).

As a comparison, we investigated the warning and mobbing calls of the Australian magpie (Gymnorhina tibicen tibicen), chosen because it is not exclusively a grounddwelling species and is of a size and weight range larger than that of typical avian prey species [10]. However, magpies do have some predators [11], especially of eggs, nestlings and, very occasionally, of fledged juveniles. Hence, we investigated whether Australian magpies produce predator-specific alarm calls.

We also chose to study the warning and mobbing calls of Australian magpies as an ideal model for investigating sensitivity to and communication about potential predators for several additional reasons. First, the Australian magpie is a songbird with a vast vocal repertoire $[12,13]$, some of which is shared with magpies in neighbouring territories $[14,15]$. Males and females both sing and do so all year round [16], they live in family groups, feed exclusively on the ground but are very accomplished flyers, roost in trees, and are territorial [17]. Second, magpies play an important role in any predator alerts in their territory, also warning avian heterospecifics [18]. Third, they have a sizeable number of alarm calls $[19,20]$, which suggests that these vocalisations might have specific communicative functions. Fourth, they orchestrate well-executed attacks, involving direct attacks preferably at the back of the neck of a predator [18]. During the breeding season, magpies are also known to treat 
unfamiliar human passers-by as intruders with similar attack styles as used for predators [21].

Our aim was to compare the vocal responses of magpies to known predators and to ascertain whether they use their large catalogue of alarm calls in any discernibly consistent manner when presented with different potential predators known to occur in the vicinity of the magpies' territories. It was hypothesised that magpies may have a lexicon of alarm calls reserved for specific predators since their success as a species appears to derive partly from their ability to cooperate and recruit members to the scene at any time of perceived risk. In other words, we predicted that the avian predators might elicit different alarm calls than the monitor lizard, and that the frequency of producing some calls might vary with perceived threat, and hence arousal levels.

\section{METHODS}

The magpies tested were black-backed and belonged to the subspecies Gymnorhina tibicen tibicen, found in much of eastern Australia, including coastal regions [22]. Before we commenced our experiments, we located the groups of magpies to be tested and determined the boundaries of their permanent territories, as well as the number of birds resident within a territory. Group sizes varied from 3 to 7 magpies with a mean of 4 per group. Groups in 39 localities were tested. A second test was made in six of these localities one year later: because these presentations were separated by 12 months, occupancy of the territory could well have changed.
Hence, these 6 scores were included with the other 39 scores and treated as independent measures (total of 45 tests).

\section{Stimulus Selection}

We tested the magpies' responses to predators, using a taxidermic model of a little eagle (Hieraaetus morphnoides), a wedge-tailed eagle (Aquila audax) and a varanid, or monitor lizard (Varanus varius), as the ecologically most likely predatory risks for magpies (Fig. 1). The wedge-tailed eagle, the largest raptor of Australia, is known to prey on birds [23], which comprise about 10 to $28 \%$ of its diet, depending on region $[11,24]$. Magpies have been found to comprise only $0.6 \%-3.5 \%$ of their diet $[25,26]$. The majority of the little eagle's diet consists of mammals, mainly rabbits [27] but, when rabbits are not available, the majority (77\%) of its diet consists of birds. Of the birds in its diet, 6\% are magpies at times outside the magpie's breeding season, rising to $18 \%$ when magpie fledglings are available [28]. Birds are also a part of the diet (about 14-16\%) of varanid lizards [29, 30], obtained by foraging on the ground as well as by climbing trees to prey on eggs and nestlings, but the contribution of magpies to this is unknown.

We did not include presentation of species that are not predators of magpies since a large number of tests conducted previously had established that magpies do not mob or vocalise in response to presentation of either a taxidermic specimen of a parrot, an eastern rosella (Platycercus eximius), a species that eats seed, in 72 tests [31] or a
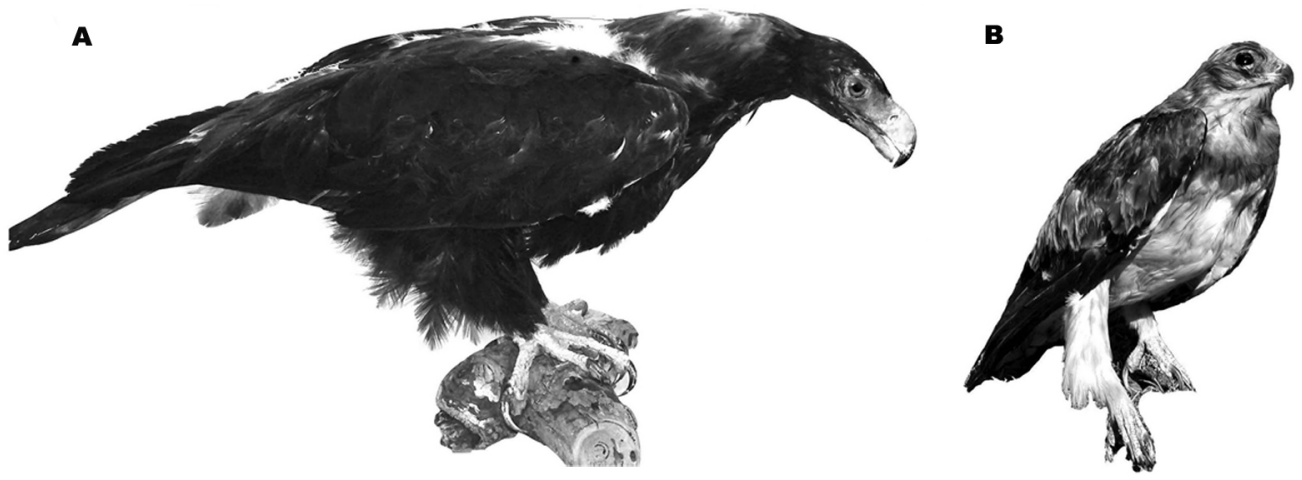

C

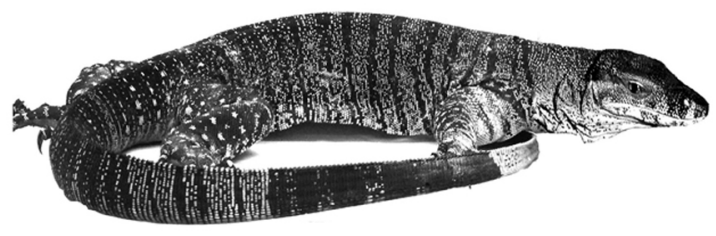

D

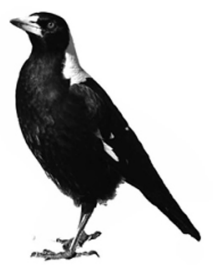

ig. (1). Taxidermic specimens (A-C) presented to the magpies. A, Wedge-tailed eagle. $87-104 \mathrm{~cm}$, wingspan $185-230 \mathrm{~cm}$; weight 3 - $4.2 \mathrm{~kg}$ (males) and $4-5.5 \mathrm{~kg}$ (females). Main hunting techniques: glide attacks, direct-flying attacks or tail-chasing attacks; majority of prey captured on the ground. B, Little eagle. $45-55 \mathrm{~cm}$, wingspan $110-135 \mathrm{~cm}$, weight $630-700 \mathrm{~g}$ (males), $700-900 \mathrm{~g}$ (females); prey capture mainly by soaring flights from on high or attacks from perches [40]. C, Monitor lizard, 1.5 to $2 \mathrm{~m}$, weight to $14 \mathrm{~kg}$, hunts in trees and on the ground. D. Australian magpie (image of live bird) for comparison; 36-44 cm, weight 300-450g. Black bar indicates $5 \mathrm{~m}$. 
stationary model of a snake that was clearly not a predator of magpie's nests, in 48 tests [32].

\section{Stimulus Presentation}

Each stimulus was presented as close to the centre of the group's territory as possible to avoid debates about the relative significance of intrusions at edge versus centre of a territory [33]. For any given test, the stimulus was placed on the ground and the tester retreated to a distance of at least $20 \mathrm{~m}$ and hid behind a bush or available structure, from where all vocalisations were recorded. Recording during presentation of the stimulus commenced at a magpie's first vocalisation or first approach to the stimulus (to within $5 \mathrm{~m}$ of the stimulus). Vocalisations were recorded for 5 min prior to testing, during testing $(5 \mathrm{~min}$ ) and $5 \mathrm{~min}$ post testing (note that the magpies did not move away when the experimenter took the stimulus away). The stimuli were presented in random order and each group was presented with only one of the stimuli. The number of magpies present at the site at the time of presentation of the stimulus was recorded.

We further recorded the number of attack swoops directed at the stimulus. This was the most direct measure of the mobbing response, apart from vocalisations. We scored an attack swoop if the magpie took a direct, high-speed flight at the stimulus and came within $2 \mathrm{~m}$ of it. Swooping frequently involved pecking at the stimulus and making a clapping sound with the beak.

Presentations of the stimuli were made between the months of March (autumn) and early December (summer) over 2 years, including two breeding seasons (locally largely between July- October) and overlapping with the breeding seasons of wedge-tailed eagles (locally between July and September) and the little eagle (locally between AugustOctober).

\section{Location of Testing Sites}

One set of experiments tested groups of magpies located in the region of Armidale, NSW, Australia $\left(30^{\circ} 32^{\prime} \mathrm{S}\right.$, $\left.151^{\circ} 40^{\prime} \mathrm{E}\right)$, a rural township. A total of 30 tests were conducted using different groups of magpies within the city boundaries of Armidale and the adjoining campus of the University of New England. These localities, termed semirural, consisted largely of grassed open parkland areas with sparse tree cover. As they were frequented by humans, these magpies were invariably habituated to the presence of humans (the magpies continued foraging within a metre of human passers-by) and these locations afforded clear visibility of their activities. In all these localities, wedge-tailed eagles and little eagles were sighted over the period during which the experiments were conducted. Monitor lizards are present in the broader environs of Armidale but not in these semi-rural locations.

In addition, we also tested the responses of magpies living in sparsely populated rural areas, with much less exposure to humans but more exposure to predators. To simulate natural conditions, for the latter rural groups (15 tests conducted on different groups), we were mindful of the natural distribution of these predators. We chose one locality as typical wedge-tailed eagle habitat $30-50 \mathrm{~km}$ from Armidale $(\mathrm{N}=11$ tests each on a different group). The monitor lizard was also presented to four (rural) groups (4 tests) in a habitat known for abundance of monitor lizards, near Glenreagh in the Coffs Harbour hinterland (30 $\left.03^{\prime} \mathrm{S}, 152^{\circ} 59^{\prime} \mathrm{E}\right)$ and also known to support the two avian predators that we presented.

In summary, a total of 45 tests were conducted using 45 groups of magpies, each group of magpies being presented with one stimulus only. The wedge-tailed eagle and the monitor lizard were presented in both semi-rural and rural environments but the little eagle was presented only in the semi-rural environment.

\section{Analysis of Sonagrams}

The vocalisations were recorded using a Tascam DAT recorder (model DA-P1) and a Sennheiser microphone (model ME66+K6P) mounted on a tripod and placed alongside the tester pointing towards the stimulus.

Recordings were analysed using Raven sound analysis software (Version 1.2.1, Cornell Laboratory of Ornithology). For each five-minute test period a frequency-time graph (sonagram) was generated. Numbers of each call type in each segment were counted and tabulated. This procedure ensured accuracy of counting calls and of determining the pattern of the different call types over time (see Table 1).

\section{Classification of Vocalisations}

Sonagrams of the call types showed that all contained many harmonics (frequencies of integral multiples of the fundamental harmonic). Several parameters were used to classify calls into five distinct types: (1) number of syllables, (2) shape of each syllable, (3) distribution of energy in the harmonics and (4) the frequency of the dominant (i.e. the visible harmonic with the greatest energy) for each syllable. Using these criteria, five distinctly different types of alarm calls were identified in response to the presentation of predators, labelled $\mathrm{A}$ to $\mathrm{E}$ in order of syllable complexity (see Table 1 for description of the calls and Fig. (2) showing sonagrams of typical examples of each type of call). Call B has been referred to in other papers [20] as a 'generic' alarm call because this call has been found to vary little and to be used widely also in contexts of low threat and in interspecific conflicts and Call C, similarly, has a wider application and is used in cases of any territorial intrusion, also by other magpies $[12,20]$.

Call A has a single syllable with the dominant harmonic of constant or near constant frequency of $1.875 \pm 0.039 \mathrm{kHz}$ (mean + sem, $n=10)$ and has a harsh sound. Call B is a low pitched call, consisting of a single syllable with the dominant decreasing regularly in frequency, through about $500 \mathrm{~Hz}$ from start to finish. The mean frequency midway through the dominant is shown in Table $\mathbf{1}$. The starting points of consecutive harmonics are spaced at about $1 \mathrm{kHz}$ apart. This call is not as harsh as call A, probably due to the harmonics being further apart.

Call $\mathrm{C}$ has a single syllable with the harmonics decreasing in frequency from start to finish and with little variation in the distribution of energy in the harmonics (in contrast to calls A and B). Also, the harmonics are further apart (typically 2 to $2.5 \mathrm{kHz}$ apart in starting frequency) than in calls $\mathrm{A}$ and $\mathrm{B}$, making this call more tonal. Some types of call $\mathrm{C}$ 
Table 1. Description of Five Classes of Alarm Calls Identified

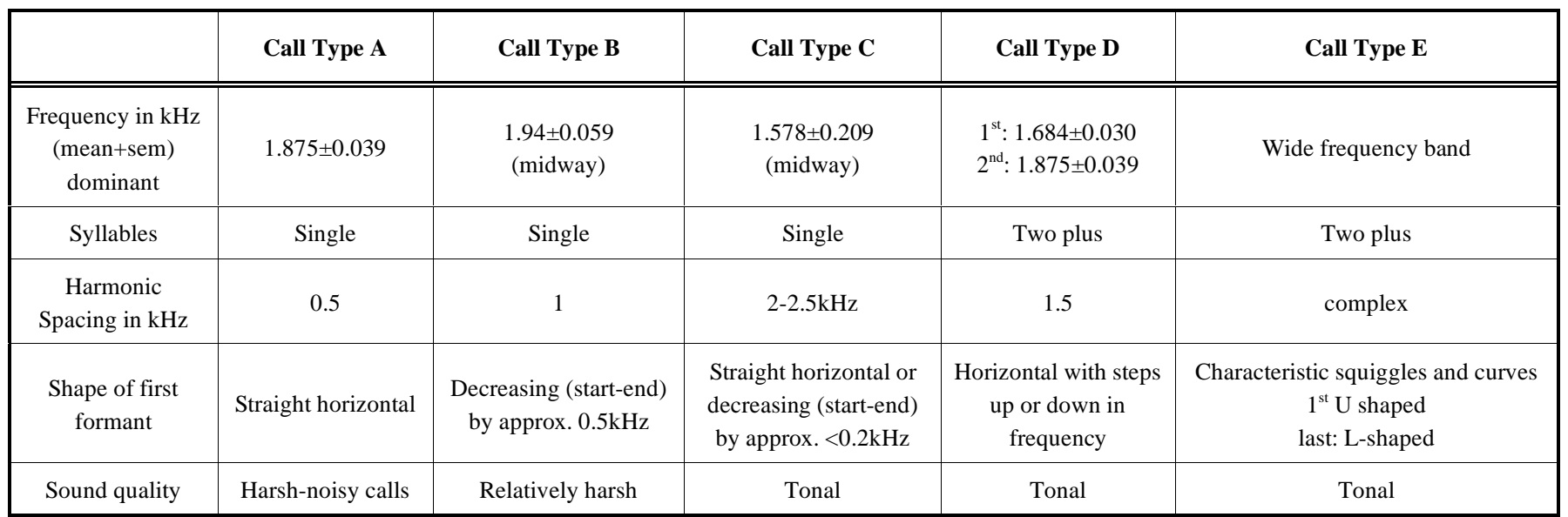

The main features of the types of call have been determined by taking measurements of 10 calls of each type. Mean and standard errors are presented.
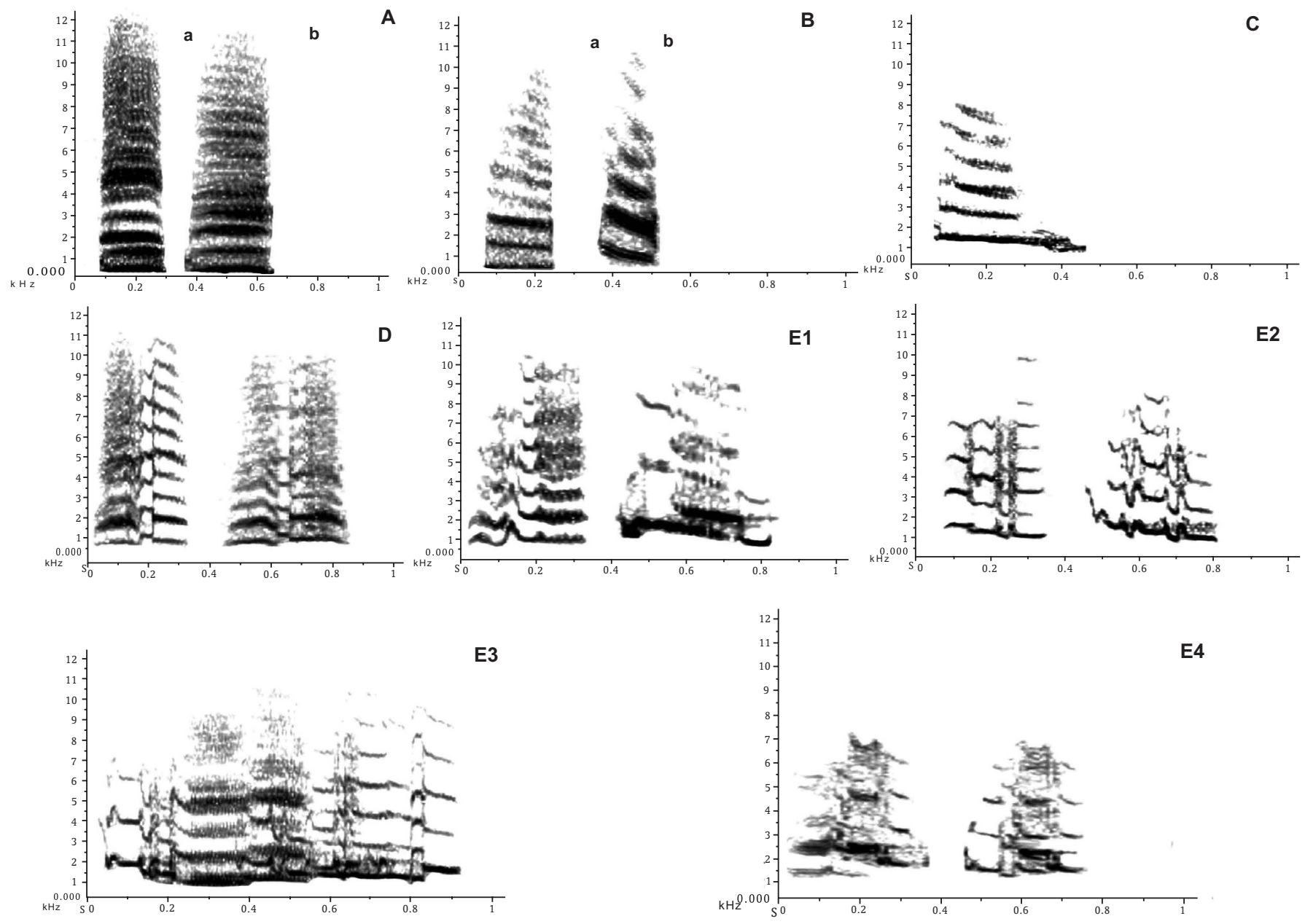

Fig. (2). Sonagrams of calls elicited by the stimuli categorised into types $\mathbf{A}$ to $\mathbf{E}$. A (a, b) are noisy calls, also produced in territorial conflicts. Examples E1 to E4 are all classified as type $\mathbf{E}$ calls: note the convoluted first formant of these $\mathbf{E}$ calls with characteristic peaks and L shaped endings. See Table for descriptive details of each call.

have a transient at the beginning, which is difficult to detect by the human ear.

Call D consists of two, clearly audible syllables that vary in relative length. In most cases the dominant formant of each syllable is of constant or near constant frequency (Table
1). In a very small number of examples of call $D$ the second syllable is more complex than the first, containing extra sonagram traces, possibly extra overtones.

Call E category includes complex calls composed of more than two syllables (examples E1 to E4 in Fig. 2). Since 
the distinction between syllables is not particularly obvious, it could be argued that the call is a single complex syllable. Nevertheless, we will consider possible syllables: the first syllable, of undulating frequency, is the most complex and variable, sometimes appearing as a series of connected Ushapes. The second syllable is always U-shaped and the last is L-shaped with an elongated tail. Variation in call E is always due to variation in the first syllable. Calls in this category have a recognisable structure and they have a tonal sound.

\section{Data Analysis}

The number of each call type was determined for the total time of recording during the presentation of the stimulus and commencing with the first response by the magpies (see earlier). These scores were weighted for number of birds present at the time of making the recording to allow comparisons to be made across groups and presentations (justified below). The scores were analysed, using SPSS, first by one-way multivariate analysis of variance (MANOVA), and then by ANOVA and post hoc LSD tests to locate significant differences. Where appropriate, Pearson's product-moment correlations were applied. The scores for swooping were analysed for an effect of stimulus type by one-way ANOVA.

\section{RESULTS}

\section{General Observations}

Presentation of both the little eagle and the wedge-tailed eagle elicited high levels of vocalisations and attack swooping flights (Fig. 3). However, on presentation of the monitor lizard, the magpies vocalised and tended to approach it closely and, instead of swooping at it, they came to the ground and performed a specific behaviour of fluttering up and down, sometimes jumping over it (height up to $1 \mathrm{~m}$ ), but they did not swoop and attack it.

Analyses of the swooping data by ANOVA (semi-rural localities only) revealed a significant main effect of stimulus $\left(\mathrm{F}_{(2,26)}=5.226, \mathrm{p}=0.012\right)$. Post hoc tests showed that the swooping responses to the monitor lizard were significantly lower than those given to the little eagle $(\mathrm{p}=0.048)$ and to the wedge-tailed eagle $(p=0.015)$. Responses to the two avian predators did not differ significantly $(\mathrm{p}=0.865)$.

The mean number of birds per group \pm sem present during the tests was $4.34 \pm 0.23$ (range 2 to 7 birds) and the total number of calls per minute correlated positively with the number of birds present $(n=45, r=0.682, p=0.000)$. Weighting the number of calls by the number of birds present (calls/bird/min) removed this association $(n=45$, $\mathrm{r}=0.237, \mathrm{p}=0.117$ ), showing that this correction for number of birds was appropriate to allow comparison across presentations and groups. This was also the case for each call considered separately: after dividing the scores by the number of birds present, $r$ values for correlation with group size were determined and they ranged from 0.001 to 0.16 and $p$ values from 0.14 to 0.99 . In fact, weighting the score for number of birds present was a conservative approach for considering the alarm calls, since the calls recruit birds to the location of the stimulus in order to mob rather than retreat from the predators. Nevertheless, it was also important to take into consideration variation of group size according to stimulus presentation when interpreting the results.
ANOVA of the scores for number of birds per group, at the time of testing, with the factor stimulus revealed a significant effect $\left(\mathrm{F}_{(4,40)}=3.106, \mathrm{p}=0.026\right)$ and post hoc LSD tests located the difference to larger groups size being recorded during presentation of the little eagle in the semirural locations (mean, $5.9 \pm 0.5$ birds/group) compared to group size for the other stimuli presented in the semi-rural locations (wedge-tailed eagle, 3.4 \pm 0.6 birds/group; lizard, $3.6 \pm 0.6 \mathrm{birds} /$ group) and the stimuli presented in the rural localities (wedge-tailed eagle $4.4 \pm 0.8$ birds/group; lizard $3.0 \pm 0.4$ birds/group).

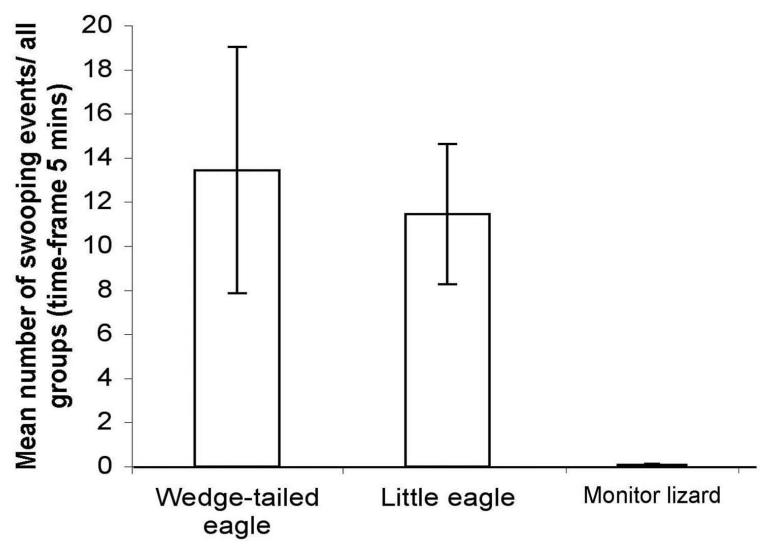

Fig. (3). Number of attack swoops directed at the stimuli presented in the semi-rural location. The data are presented as mean number of swoops/bird/min with standard error bars. Note that this aspect of mobbing behaviour is directed at the two eagle models presented and not the monitor lizard.

\section{Overall Pattern of Call Production}

The total number of calls/bird/min did not vary according to the stimulus presented $\left(\mathrm{F}_{(4,40)}=0.492, \mathrm{p}=0.741\right)$. Hence, any variation in the vocalisations made during presentation of the stimuli is due to differences in the pattern of the various types of calls (below) and not to differences in calling rate overall. The score for the number of each call type were considered irrespective of the stimulus presented. Over the 5 min of recording, calls $\mathrm{A}$ and $\mathrm{D}$ were the most common and calls B, C, and E were emitted less frequently (Fig. 4). However, the calls occurred at different times during the predator presentations. At the time of recruitment of other magpies (first minute of the five minute presentation), D and $\mathrm{E}$ were the most common calls while, at the time of actual swooping attacks, A, interspersed with B and C, was the most common call (details next section).

\section{Variation in Call Types with Respect to Stimulus}

The number of calls/bird/min collected for the three stimuli according to locations were analysed by one-way multivariate analysis of variance. This revealed significant variation in the suite of calls elicited by the three stimuli/ locations (Wilks' Lambda $=0.331, \mathrm{~F}_{(20,120)}=2.382, \mathrm{p}=0.002$ ); see Fig. (5).

Further univariate analyses showed that, of the five calls comprising the suite, calls D and E varied significantly 
across the stimuli (call $\mathrm{D}, \mathrm{F}_{(4,40)}=2.952, \mathrm{p}=0.032$; call $\mathrm{E}$, $\left.\mathrm{F}_{(4,40)}=4.418, \mathrm{p}=0.005\right)$. Call $\mathrm{A}$ did not vary significantly between stimuli $\left(\mathrm{F}_{(4,40)}=2.141, \mathrm{p}=0.093\right)$ and nor did call $\mathrm{B}$ $\left(\mathrm{F}_{(4,40)}=2.127, \mathrm{p}=0.095\right)$ or call $\mathrm{C}\left(\mathrm{F}_{(4,40)}=2.260, \mathrm{p}=0.080\right)$. However, note that all were significant at the $\mathrm{p}=0.10$ level.

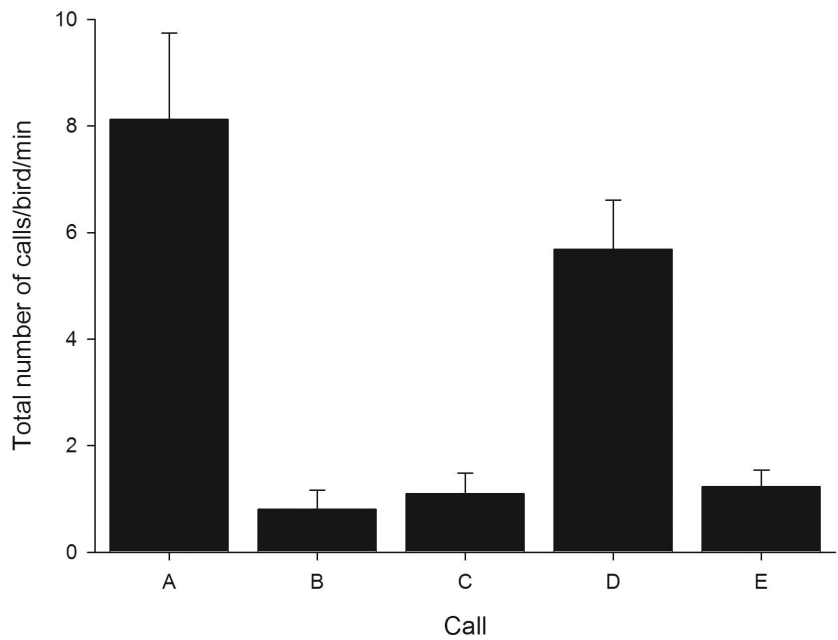

Fig. (4). Total number of calls/bird/min presented for calls $\mathbf{A}$ to $\mathbf{E}$. Means and standard errors bars are presented, calculated without taking stimulus into account, simply to indicate overall calling rates for each type of call.

Post hoc LSD tests showed that the variation in Call D was due to the call being evoked more commonly by presentations of the wedge-tailed eagle in the rural localities and the little eagle in the semi-rural localities: the significant post hoc tests were wedge-tailed eagle semi-rural versus a) lizard semi-rural $(\mathrm{p}=0.035), \mathrm{b})$ lizard rural $(\mathrm{p}=0.009)$ and $\mathrm{c})$ wedgetailed eagle rural $(\mathrm{p}=0.040)$, as well as little eagle semi-rural versus lizard rural $(\mathrm{p}=0.022)$.

The most consistent variation across stimuli occurred for Call E. This call was emitted most frequently on presentation of the little eagle in semi-rural localities and the wedge-tailed eagle in rural localities: post hoc LSD showed that the response to the little eagle was significantly higher than it was to the wedge-tailed eagle in semi-rural localities $(\mathrm{p}=0.030)$, the lizard in semi-rural localities $(\mathrm{p}=0.020)$ and the lizard in rural (lizard habitat) localities $(\mathrm{p}=0.057)$. Significantly more E calls were elicited by the wedge-tailed eagle in the rural localities than in the semi-rural localities $(\mathrm{p}=0.004)$ and by this stimulus compared to the lizard in either locality (semi-rural, $\mathrm{p}=0.003$; rural lizard, $\mathrm{p}=0.015$ ).

Calls D and E were produced near the commencement of calling after presenting the stimulus (i.e. on first sight of the stimulus); the first Call $\mathrm{E}$ was produced within the first 20 sec in $58 \%$ of presentations and continued throughout the period of presentation of the little eagle in semi-rural localities and the wedge-tailed eagle in rural localities. In fact, Calls D and E were the most common calls made within in the first 20 seconds, especially during presentation of the wedge-tailed eagle. On presentation of the eagles, Call A was rarely made in the first minute: production of these calls started after approximately a minute's delay and then continued throughout the presentation of the stimulus, coincident with the swooping attacks. By contrast, on presentation of the lizard, frequent production of Call A began immediately.

\section{Arousal}

Calling rate of a specific call might indicate the individual bird's state of arousal. To estimate what call type(s) might be most likely to indicate the bird's state of arousal, we correlated each call (number/min) with the total number of calls/bird/min. The only call to show an association was Call A (Pearson's Correlation, $\mathrm{r}=0.618, \mathrm{p}=0.000, \mathrm{n}=45$ ). Since call A is common, this might be a trivial finding, had these not been an absence of such an association for Call D $(\mathrm{r}=0.140, \mathrm{p}=0.358, \mathrm{n}=45)$, which occurs almost as frequently as Call A. Call D, it seems, occurs with variable rate between individuals, whereas Call A may reflect the general state of arousal. Call A does not signal specificity of the stimulus. The absence of any association between Call $\mathrm{E}$ and the total number of calls is noted in particular $(\mathrm{r}=0.239, \mathrm{p}=0.114$, $\mathrm{n}=45$ ) since this suggests that Call $\mathrm{E}$ does not signal level of arousal, but rather type of stimulus (predator).

\section{Vocal Behaviour Pre-Test, Test and Post-Test}

The number of alarm calls that were recorded before or after the presentation of the stimuli were zero or so negligible that it is not necessary to show these scores in a figure. Vocalisations were made only after the magpies had sighted the stimulus. The magpies were usually stationary and silent in the pre- and post-test periods, lending considerable weight to the observation that the calls were related to the stimulus presented at the time. The vocal behaviour was always followed by or was expressed in conjunction with attack (swooping or jumping) and approach behaviour.

\section{DISCUSSION}

Swooping at predators is one of the common mobbing responses of the Australian magpie [18,21,34] and it was readily elicited by the specimens of two species of eagles that we presented. Regardless of the fact that we presented the model eagles on the ground, the magpies must have perceived them to be a threat. We have also observed magpies mobbing live eagles on the ground in the same way.

The tests in the semi-rural localities revealed that the taxidermic specimens of the little eagle and the wedge-tailed eagle elicited the same amount of swooping per magpie (i.e. for these two stimuli, there was no difference in number of swoops/bird/min), but the little eagle recruited more magpies than did any of the other stimuli. This might suggest several things, such as familiarity with the predator, likelihood of risk from the predator and ability to dislodge the predator. In the semi-rural environment, the little eagle was the more likely target for vigorous attack than the wedge-tailed eagle or the monitor lizard. Little eagles are common on the Northern Tablelands of New South Wales, whereas wedgetailed eagles have become far less common although they are still seen. At the time of the experiments, two breeding pairs of little eagle were known to live in the Armidale vicinity. This might suggest that the magpies in the semi-rural localities perceived the little eagle as somewhat more threatening than the wedge-tailed eagle (both in numbers and in likelihood of attack) and this is also consistent with the greater 

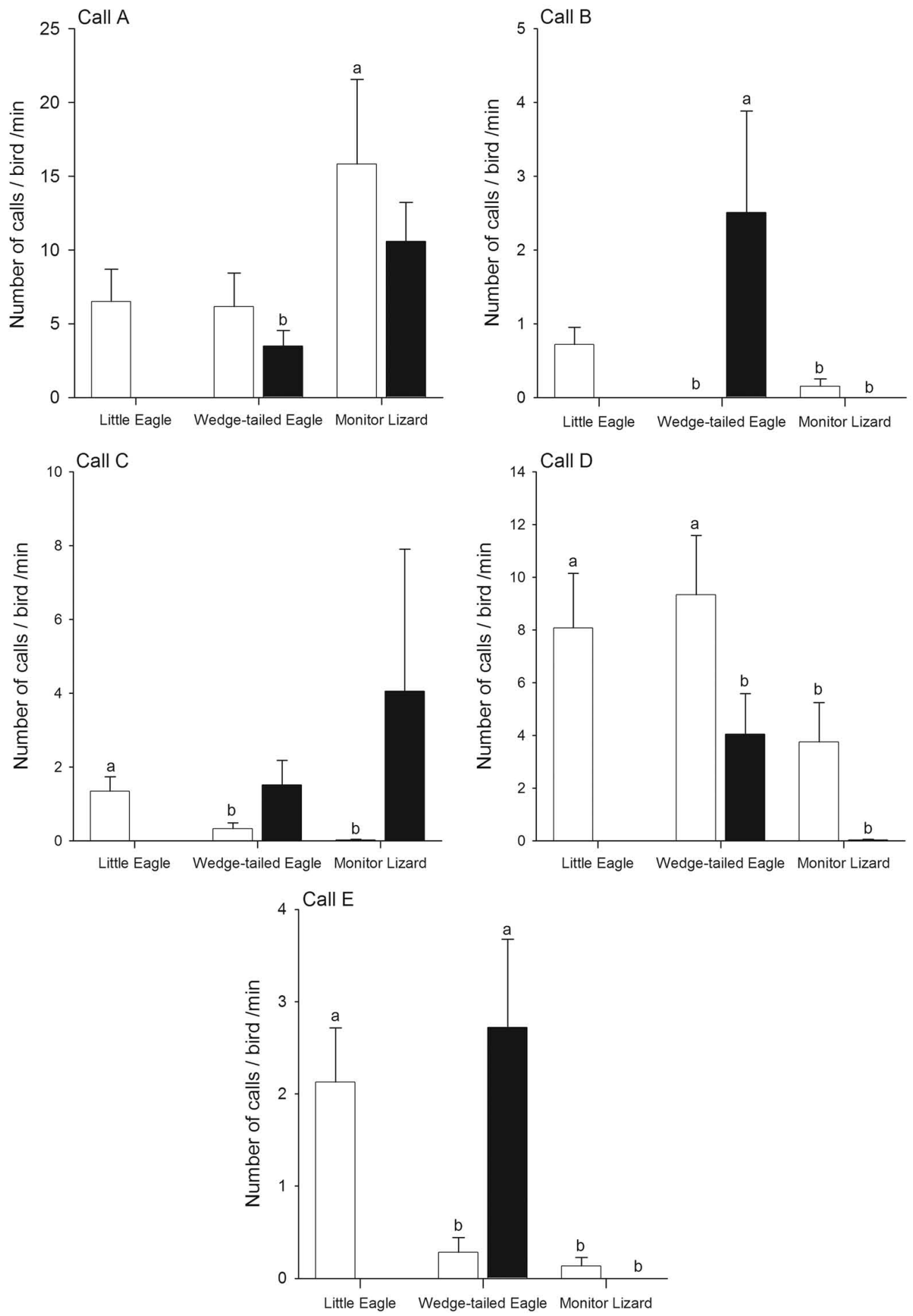

Fig. (5). Number of calls/bird/min is presented for each stimulus, as means and standard errors, and for each call type. White bars indicate presentations in semi-rural locations and black bars in rural locations. Note that the little eagle was presented only in the semi-rural environment (white bars only). As the wedge-tailed eagle and monitor lizard were presented in both the semi-rural and rural environments, the absence of a white of black bar for these stimuli means that the scores were zero. Bars marked 'a' differ significantly from those marked ' $b$ ', LSD tests.

proportion of birds in the diet of the little eagle than in that of the wedge-tailed eagle [28].

The magpies' behavioural responses to the taxidermic model of the monitor lizard were quite different from those to the avian predators, probably because mobbing a large lizard on the ground, rather than swooping at it from above, may be a way of directing this predator away from the nest and the territory. Vocal distinction in alarm calling between aerial and ground predators is made by many prey species $[35,36]$ and it is important to note here that the tactics of attack used by the magpies clearly distinguished between 
ground and aerial predators, despite the fact that all of the stimuli were presented on the ground. They did not swoop at the monitor lizard either in the semi-rural or rural (coastal) localities. The magpies approached the monitor lizard stimulus but did so on the ground with fluttering flights of no more than a metre above ground level and sometimes they jumped over the lizard.

The magpies vocalised frequently during stimulus presentations but did so either not at all or very rarely in the pre- and post-presentation periods. Hence, the calls recorded were elicited by the stimuli and, therefore, must all signal the presence of a threat and/or a recognised predator. Moreover, as we know from previous experiments (see Methods), no vocalisations or other mobbing behaviour are elicited by models of avian or reptilian species that are not predators of magpies. The vocalisations made are, therefore, specifically in response to seeing a predator.

Previous researchers have shown that social facilitation contributes to mobbing in other species, not only of display responses but also of vocalisations. Zebra finches, for example, increase the rate of calling per individual linearly with increasing flock size [37]. This pattern was not apparent in our data: the calling rate of each individual magpie did not correlate with the number of birds present. The total number of calls made correlated significantly with the number of birds present but each bird contributed calls at the same rate irrespective of group size. In other words, although the alarm calls may recruit other individuals to mob the predator, the magpies show no social facilitation in terms of calling rate per individual.

The total number of calls per presentation did not vary according to stimulus but the pattern of vocal responses differed according to stimulus. Calls A (noisy call) and D (tonal call) were the most frequently made calls and our results show that the rate of producing Call $\mathrm{A}$, but not call $\mathrm{D}$, correlated with the total calling rate. Hence, it is likely, and consistent with the nature of mobbing calls, that Call A, and not Call D, indicates the general state of arousal. Magpies use the same Call A also in territorial disputes with neighbours [12]. Call A appears to be a mobbing call employed within close proximity of the stimulus. The harsh and high amplitude characteristic of Call A make it suited for this function $[12,20]$. Our results thus suggest that Call A may not be a vocalisation signalling the presence of a specific predator but rather a call signalling arousal. Call A was, however, given most commonly on presentation of the monitor lizard. Our results are inconclusive but the difference could be due to differences in level of arousal, if the monitor lizard was perceived as a greater threat than the eagles. However, this is rather unlikely in the semi-rural localities, where monitor lizards do not occur. Hence, Call A could, possibly, signal the presence of a different type of predator (not an aerial predator, although it must be noted that monitor lizards do climb trees to prey on birds' eggs).

Calls B and C failed to show significant specificity for the stimulus/locality although there was a trend towards significance $(0.05<\mathrm{p}<0.10)$ in both cases. Call type B has been recorded in other contexts and has been heard in conjunction with and in the context of a large variety of territorial infringements or disputes among magpies [18]. This call has been called 'generic' in the sense that it is a general alarm call and has been heard in the other subspecies of magpies so far tested, that is in Melbourne, Canberra and in Tasmania near Hobart [18,38,39]. This particular call tends to be more stereotyped than others and is not often associated with attack but it does lead to a cessation of foraging by other magpies and usually to direct alert viewing of the environment [12,38]. Call $\mathrm{C}$, interestingly, has been recorded in other contexts most often in aerial disputes between magpies and, at times, in serious inter-group disputes [18]. Notably, all three categories (A,B,C) are single syllable calls. A and B are rarely more than $0.2 \mathrm{sec}$ in duration and even $\mathrm{C}$ lasts only 0.4 secs.

Call D, the two-syllable call, was elicited by both eagle models in the semi-semi-rural localities and at high rates (about 8 to 10 calls per minute by each bird). Significantly fewer numbers of Call D were elicited on presentation of the lizard in the semi-rural localities and this call was not elicited at all by the presentation of the lizard in the rural (coastal) localities. These results suggest that Call D may chiefly, although not exclusively, signal the presence of an aerial/ avian predator. However, it was rarely elicited by presentation of the wedge-tailed in the rural localities, perhaps because Call E replaced it in this context, as we discuss next.

The most complex call, Call E, not previously described in the literature, varied significantly across stimuli and localities. It consists of extremely high amplitude elements in which the syllables run into each other without breaks (and breathing) and can last for an entire second (Example Fig. (2), E3) or even up to two seconds. In our experiments, it was produced most frequently in response to presentations of the little eagle in the semi-rural localities, where this species is an active predator, and the wedge-tailed eagle in the rural localities, where this species is an active predator.

Call E was not elicited by presenting the monitor lizard in either semi-rural or rural localities. Hence, it can be said that Call $\mathrm{E}$ is specific for threat of predation by eagles. Importantly, as the first Call $\mathrm{E}$ was usually produced within the first 20 seconds of presentation of the eagle models, it may be a referential alarm call issued to alert group members to the presence of an eagle predator. This warrants further investigation.

Hence, we have found an alarm call (E) that signals the presence of eagles in localities where they represent a significant threat (i.e. are active predators). Call E, therefore, may signal not only type of predator but also degree of threat. There is no evidence to date that call $\mathrm{E}$ is used in contexts other than response to birds of prey (i.e. not for conspecific intrusion of a territory or for other predators such as the monitor lizard). It would be premature to claim that we have also found a specific signal for the monitor lizard but the single syllable Call B, in conjunction with Call A, may serve this function.

It is worth considering why the more complex call (E) might refer to the presence of an eagle, whereas the simple calls $(\mathrm{A}, \mathrm{C})$ are elicited more commonly in response to a monitor lizard. Chickens, Gallus gallus domesticus, also use a harsh call to refer to a ground predator and a longer, higher pitched call to refer to an aerial predator [35]. Call A is a harsh sounding call that appears to be part of the magpie's 
mobbing response (ground fluttering and jumping) used in order to drive the monitor lizard away.

Magpies responded most strongly and most unambiguously to taxidermic models that corresponded to high prevalence of the same species in the region. These strongly differentiated vocal responses suggest not only a sophisticated level of discrimination as reflected in the birds' vocalisations, but also that these calls may be made intentionally and referentially [39]. Call E readily recruited all members of the magpie group to the scene of the first calling magpie and led, invariably, to well-coordinated attacks.

Distinct and loud calls that carry over long distances are further suggestive of an excellent system of communication between group members, as has been studied in other avian species not so prone to predation (e.g. pinyon jays [40]; starlings [41]. Magpies have territories ranging in size from 2-100 hectares [42] and recruitment of group members may well be achieved by calls of type $\mathrm{E}$ which, in their complex structure, tonal distinctness and high frequency range and amplitude (110-120dB) carry over long distances (over 1.5 $\mathrm{km}$ ) and are suited for open woodlands and grasslands. Unlike the alarm calls of smaller prey species, those of magpies are not warning calls leading to withdrawal and flight but rather they recruit other group members to the site and are calls to attack [39].

Early warning permits small prey species to seek appropriate shelter and save precious seconds in finding a safe hiding spot. By contrast, early warning in magpies may lead to greater caution when approaching and strategic preparedness for high-risk situations but magpies do not hide. Instead, the calls bring them out in the open and together. Playback of these calls to magpies will allow us to test the proposed functions of these calls and determine whether Call $\mathrm{E}$ is a referential signal. This species has an arsenal of behavioural defences, exceptional vigilance, group cohesion and an efficient communication system.

\section{CONCLUSION}

The Australian magpie has a range of alarm calls produced in response to seeing predators, and all calls are produced, for example, when they see eagles. The harsh, monosyllabic Call A appears to signal the state of arousal. The most acoustically complex of their calls (E) is produced only when they see an eagle (aerial predator) in a context where this predator represents a serious threat to their young and maybe also to the adult birds. The monitor lizard usually elicits none of these complex calls but more of the simple, harsh, single-syllable calls. The monitor lizard also elicits mobbing at ground level and not the aerial swooping displayed to eagles. Eagles are swooped when they are on the ground. Hence, the vocal and other behavioural strategies used in mobbing differ for aerial/avian predators versus the monitor lizard. The alarm calls elicited by the model predators varied with location (semi-rural versus rural), which may depend on whether the predator is a genuine threat to survival in the particular locality tested.

\section{ACKNOWLEDGEMENTS}

This research was funded by an ARC-discovery grant to L.J.R. and G.K. We are most grateful to R. MacKay for preparing the taxidermic specimens.

\section{REFERENCES}

[1] Seyfarth RM, Cheney DL, Marler P. Monkey responses to three different alarm calls: evidence of predator classification and semantic communication. Science 1980; 210: 801-3.

[2] Digweed SM, Fedigan LM, Rendall D. Variable specificity in the anti-predator vocalizations and behaviour of the white-faced capuchin, Cebus capucinus. Behaviour 2005; 142: 997-1021.

[3] Sproul C, Palleroni A, Hauser MD. Cottontop tamarin, Saguinus oedipus, alarm calls contain sufficient information for recognition of individual identity. Anim Behav 2006; 72: 1379-85.

[4] Wich SA, de Vries H. Male monkeys remember which group members have given alarm calls. Proceedings of the Roy Soc Lond B 2006; 273: 735-40.

[5] Yorzinski JL, Vehrenkamp SL, Clark AB, McGowan KJ. The inflected alarm caw of the American crow: differences in acoustic structure among individuals and sexes. Condor 2006; 108: 518-29.

[6] Alatalo RV, Helle, P. Alarm calling by individual willow tits, Parus montanus. Anim Behav 1990; 40: 437- 42.

[7] Marler P, Evans C. Bird calls: just emotional displays or something more? Ibis 1996; 138: 26-33.

[8] Edelaar P, Wright J. Potential prey make excellent ornithologists: adaptive, flexible responses towards avian predation threat by Arabian Babblers, Turquoides squamiceps, living at a migratory hotspot. Ibis 2006; 148: 664-71.

[9] Kiriazis J, Slobodchikoff CN. Perceptual specificity in the alarm calls of Gunnison's prairie dogs. Behav Processes 2006; 73: 29-35.

[10] Gotmark F, Post P. Prey selection by sparrowhawks, Accipiter nisus: relative predation risk for breeding passerine birds in relation to their size, ecology and behaviour. Philos Trans Biol Sci 1996; 351: 1559-77.

[11] Baker-Gabb DJ. The feeding behaviour and ecology of seven species of raptor overwintering in coastal Victoria. Aust Wildl Res 1984;11:145-60.

[12] Kaplan G. Australian Magpie Gymnorhina tibicen. Voice. (Entry 709). In: Peter J, (Sr. Ed.). In conjunction with Birds Australia, The Handbook of Australian, New Zealand and Antarctic Birds. Melbourne: Oxford University Press 2006; vol. 7: pp. 605-8, 613-16.

[13] Sanderson K, Crouche H. Vocal Repertoire of the Australian Magpie Gymnorhina tibicen in South Australia. Aust Bird Watcher 1993; 15: 162-4.

[14] Brown ED, Farabaugh SM, Veltman CJ. Song sharing in a groupliving songbird, the Australian magpie, Gymnorhina tibicen, I. Vocal sharing within and amongst social groups. Behaviour 1988; 104: 1-28.

[15] Farabaugh SM, Brown ED, Veltman CJ. Song sharing in a groupliving songbird, the Australian magpie, Gymnorhina tibicen, II. Vocal sharing between territorial neighbors, within and between geographic regions, and between sexes. Behaviour 1988; 104:10525.

[16] Deng C, Kaplan G, Rogers LJ. Similarity of the song control nuclei of male and female Australian magpies (Gymnorhina tibicen). Behav Brain Res 2001; 123: 89-102.

[17] Kaplan G. The Australian Magpie (Gymnorhina tibicen): An alternative model for the study of songbird neurobiology. In: Zeigler P, Marler P, Eds. The Neuroscience of Birdsong. Cambridge: Cambridge University Press 2008; pp. 153-70.

[18] Kaplan, G. The Australian Magpie: Biology and Behaviour of an Unusual Songbird. Sydney and Melbourne: University of New South Wales Press and CSIRO Publishing 2005.

[19] Jurisevic MA, Sanderson KJ. Alarm vocalisations in Australian birds: convergent characteristics and phylogenetic differences. Emu 1994; 94: 69-77.

[20] Kaplan G. Alarm calls, communication and cognition in Australian magpies. Symposium paper, international ornithology congress, Beijing, 2002. Acta Zool Sinica 2006; 52: 614-17.

[21] Jones DN. Magpie alert. Learning to Live with a Wild Neighbour. Sydney: UNSW Press 2002.

[22] Schodde R, Mason IJ. The Directory of Australian Birds. Passerines. Melbourne: CSIRO Publishing 1999.

[23] Hull C. The diet of the wedge-tailed eagle, Aquila audax, breeding near Melbourne. Corella 1986; 10: 21-4.

[24] Sharpe A, Gibson L, Norton M, Marks A, Ryan B, Semeraro L. An evaluation of the use of regurgitated pellets and the skeletal material to quantify the diet of Wedge-tailed Eagles, Aquila audax. Emu 2002; 102: 181-5. 
[25] Brooker MG, Ridpath MG. The diet of the wedge-tailed Eagle, Aquila audax, in Western Australia. Aust Wildl Res 1980; 7: 43352.

[26] Leopold AS, Wolfe TO. Food habits of nesting Wedge-tailed Eagles, Aquila audax, in south-eastern Australia. Wildl Res 1970; 15: 1-17.

[27] Aumann T, Baker-Gabb DJ. The ecology and status of the red goshawk in northern Australia. Royal Australasian Ornithologists Union Report, Melbourne 1991.

[28] Debus SJS. Biology of the little eagle on the Northern Tablelands of New South Wales. Emu 1984; 84: 87-92.

[29] King D, Green B. Goannas: the Biology of Varanid Lizards. Sydney: University of New South Wales Press 1999.

[30] Weaver BW. Diet of the lace monitor lizard (Varanus varius) in south-eastern Australia. Aust Zool 1989; 25: 83-5.

[31] Koboroff A. Dominant perceptual cues for predator detection by birds in open forest and edge habitats. Honours thesis, University of New England 2004.

[32] Koboroff A. Avian anti-predator strategies: specificity of mobbing and predator inspection in the Australian magpie (Gymnorhina tibicen) and the zebra finch (Taeniopygia guttata). Doctor of Philosophy thesis, University of New England 2008.

[33] Brown ED, Farabaugh SM, Hughes JM. A test of centre-edge hypotheses in a permanently territorial songbird, the Australian magpie, Gymnorhina tibicen. Anim Behav 1993; 45: 814-6.

[34] Koboroff A, Kaplan G, Rogers LJ. Hemispheric specialization in Australian magpies (Gymnorhina tibicen) shown as eye preferences during response to a predator. Brain Res Bull 2008; 76: 304-6.
[35] Evans CS, Evans L, Marler P. On the meaning of alarm calls: functional reference in an avian vocal system. Anim Behav 1993; 46: 23-38.

[36] Frederiksen JK, Slobodchikoff CN. Referential specificity in the alarm calls of the black-tailed prairie dog. Ethol Ecol Evol 2007; 19: 87-99.

[37] Lombardi CM, Curio E. Social facilitation of mobbing in the zebra finch (Taeniopygia guttata). Bird Behav 1985; 6: 34-40.

[38] Macintyre P, Kaplan G. Responses of the tasmanian subspecies of Australian magpies (Gymnorhina tibicen hypoleuca) to birds of prey. National Conference of the Australasian Society for the Study of Animal Behaviour, Coffs Harbour, 27-30 March 35 ${ }^{\text {th }}$ ASSAB Conference Program and Book of Abstracts. Armidale: UNE Printery 2008; p. 42

[39] Kaplan G. Alarm calls and referentiality in Australian magpies: between midbrain and forebrain, can a case be made for complex cognition? Brain Res Bull 2008; 76: 253-63.

[40] Dahlin CR, Balda RP, Slobodchikoff CN. Food, audience and sex effects on pinyon jay (Gymnorhinus cyanocephalus) communication. Behav Proc 2005; 68: 25-39.

[41] Hausberger M, Cousillas H. Categorization in birdsong: from behavioural to neuronal responses. Behav Proc 1996; 35: 83-91.

[42] Carrick R. Population ecology of the Australian black-backed magpie, royal penguin and silver gull, population ecology of migratory birds: a symposium, U.S. department of the interior. Wildl Res Rep 1972; 2: 41-99.

(c) Kaplan et al.; Licensee Bentham Open.

This is an open access article licensed under the terms of the Creative Commons Attribution Non-Commercial License (http://creativecommons.org/licenses/ by-nc/3.0/) which permits unrestricted, non-commercial use, distribution and reproduction in any medium, provided the work is properly cited. 